\title{
Hidradenite supurativa tratada com infliximabe *
}

\author{
Hidradenitis suppurativa treated with infliximab
}

\author{
Daniel Lago Obadia ${ }^{1}$ \\ Thiago Jeunon ${ }^{3}$
}

\author{
Egon Luiz Rodrigues Daxbacher ${ }^{2}$ \\ Alexandre Carlos Gripp ${ }^{4}$
}

\begin{abstract}
Resumo: A hidradenite supurativa é doença inflamatória de difícil tratamento. Recentemente, a terapia antiTNF alfa, com anticorpos monoclonais ("terapia biológica"), tem sido apontada como uma alternativa. No entanto, ensaios clínicos avaliando a eficácia destas drogas na hidradenite supurativa, ainda não foram publicados. Apresentamos um caso no qual o uso do infliximabe não resultou em melhora clínica expressiva. Palavras-chave: Anticorpos monoclonais; Fator de necrose tumoral alfa; Hidradenite
\end{abstract}

\begin{abstract}
Hidradenitis suppurativa is an inflammatory disease with difficult treatment. Currently, the antiTNF alfa therapy, with monoclonal antibodies ("biological therapy"), has been shown as a new alternative. However, clinical trials assessing the efficacy of these drugs to treat hidradenitis suppurativa have not yet been published. A case in which the use of infliximab did not result in significant clinical improvement is described.

Keywords: Antibodies, monoclonal; Hidradenitis; Tumor necrosis factor-alfa
\end{abstract}

A hidradenite supurativa (HS) é uma doença inflamatória crônica, com predileção por áreas ricas em glândulas apócrinas, tais como as regiões axilares, inguinais, perineal e interglútea. ${ }^{1}$ A prevalência varia de 0,33 a 4 casos por 1000 habitantes $^{2}$ e sua etiologia ainda não foi completamente elucidada. ${ }^{3} \mathrm{~A}$ HS compõe, juntamente com acne conglobata, foliculite e perifoliculite capitis abscedens et suffodiens e cisto pilonidal, um grupo de doenças clinicamente distintas, mas com achados histopatológicos semelhantes, conhecido como tétrade de oclusão folicular. Inicialmente, ocorre infundibulite supurativa e rutura folicular, com posterior infiltração inflamatória mista superficial e profunda, às custas de neutrófilos, linfócitos, plasmócitos e formação de granulo- mas supurativos. Tecido de granulação e hastes de pelo são observados em quantidades variáveis na derme. Tardiamente, fibrose e fístulas se tornam proeminentes. ${ }^{4}$ A inflamação das glândulas apócrinas, considerada no passado o processo patológico fundamental, é na realidade um evento secundário ao acometimento folicular. O curso da HS é crônico na maioria dos casos, com períodos de exacerbação e melhora, apesar das diversas opções terapêuticas frequentemente empregadas. Dentre elas, podemos citar antibióticos tópicos e sistêmicos, corticosteroide intralesional e oral, isotretinoína oral, cirurgias, crioterapia, terapia hormonal, entre outros. Recentemente, o uso de infliximabe tem sido sugerido como uma alternativa eficaz.

Recebido em 17.9.2008.

Aprovado pelo Conselho Consultivo e aceito para publicação em 9.7.09.

* Trabalho realizado na Universidade do Estado do Rio de Janeiro (UERJ) - Rio de Janeiro (RJ), Brasil.

Conflito de interesse: Nenhum / Conflict of interest: None

Suporte financeiro: Nenhum / Financial funding: None

1 Especialista em dermatologia pela Sociedade Brasileira de Dermatologia (SBD). Pós-graduado em Dermatologia pela Universidade do Estado do Rio de Janeiro (UERJ). Professor substituto do Serviço de Dermatologia da Universidade do Estado do Rio de Janeiro (UERJ) - Rio de Janeiro (RJ), Brasil.

Especialista em dermatologia pela Sociedade Brasileira de Dermatologia (SBD). Pós-graduado em Dermatologia pela Universidade do Estado do Rio de Janeiro (UERJ). Professor substituto do serviço de Dermatologia da Universidade do Estado do Rio de Janeiro (UERJ) - Rio de Janeiro (RJ), Brasil.

Especialista em dermatologia pela Sociedade Brasileira de Dermatologia (SBD). Residência em Dermatologia pela Universidade do Estado do Rio de Janeiro (UERJ). Médico/preceptor do Serviço de Dermatologia do Hospital Geral de Bonsucesso - Rio de Janeiro (RJ), Brasil.

4 Especialista em dermatologia pela SBD. Residência em Dermatologia pela Universidade Federal Fluminense (UFF). Mestre em Dermatologia pela Universidade Federal Fluminense (UFF). Professor assistente de dermatologia pela Universidade do Estado do Rio de Janeiro (UERJ) - Rio de Janeiro (RJ), Brasil. 
Apresentamos caso de paciente masculino, 49 anos, branco, que referia surgimento de nódulos eritematosos e dolorosos nas axilas e regiões inguinais, desde os 15 anos de idade, quando recebeu o diagnóstico de HS. Desde então, apresentou períodos de piora e melhora, com resposta parcial aos diversos tratamentos empregados, sem nunca ter obtido remissão completa das lesões. Fez uso oral de tetraciclinas, eritromicina, cefalexina, ciprofloxacina e isotretinoína. Há 15 anos, foi submetido à cirurgia de esvaziamento glandular das axilas e, há seis anos, recebeu prednisona oral para tratamento de pioderma gangrenoso nas pernas. No momento da consulta, encontrava-se em uso de ciprofloxacina 500 $\mathrm{mg} /$ dia e prednisona $20 \mathrm{mg} /$ dia com controle precário da condição.

Ao exame dermatológico, observavam-se nódulos eritematosos de $1 \mathrm{~cm}$ de diâmetro, com saída de secreção amarelo-esverdeada nas axilas, além de cicatrizes e fístulas cutâneas nas regiões inguinais. $\mathrm{Na}$ região sacra, havia úlcera de $7 \mathrm{~cm}$ de diâmetro e $4 \mathrm{~cm}$ de profundidade, com bordas eritematosas e saída de secreção amarelada. (Figura 1) A possibilidade de associação com doença de Crohn foi excluída através de avaliação proctológica. O paciente foi submetido a rastreamento para tuberculose ativa ou infecção prévia e, após resultados negativos, foi iniciado infliximabe na dose de $300 \mathrm{mg}(4,6 \mathrm{mg} / \mathrm{kg})$ por infusão, em um total de quatro infusões (semanas $0,2,6$ e 10). Não houve reações infusionais.

A partir da segunda infusão, houve diminuição da secreção nas lesões. No entanto, a úlcera sacral não apresentou diminuição no diâmetro ou profundidade. Durante o uso do infliximabe, pode-se reduzir a dose da prednisona para $10 \mathrm{mg} / \mathrm{dia}$, mas não houve melhora significativa, ao final das quatro aplicações. Em seguida, o paciente foi encaminhado para terapia hiperbárica, também com pouca melhora. (Figura 2)

Relatos e séries de casos têm sugerido que o infliximabe seja uma medicação eficiente para o tratamento da HS, apesar de não aprovado para esta finalidade. ${ }^{5,6,7,8}$ Fadet et al relataram ótima resposta em cinco de sete pacientes na $6^{\mathrm{a}}$ semana de tratamento, embora três tenham apresentado efeitos colaterais graves. ${ }^{5}$ Fernández-Vozmediano et al obtiveram melhora em todos os seis pacientes estudados, após a 1a infusão, com apenas uma reação infusional leve. ${ }^{7}$ A posologia sugerida é de $5 \mathrm{mg} / \mathrm{kg} / \mathrm{apli}$ cação, em infusões intravenosas nas semanas 0,2 e 6. Se necessário, uma aplicação adicional pode ser feita na $10^{\mathrm{a}}$ semana, a exemplo do que é realizado

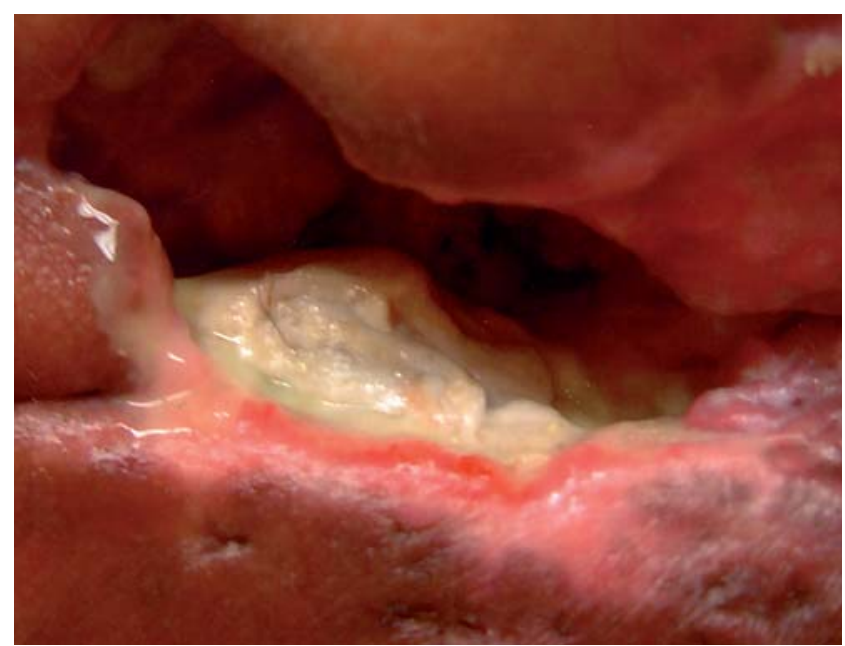

FigurA 1: Úlcera sacral com intensa secreção amarelada antes da primeira infusão

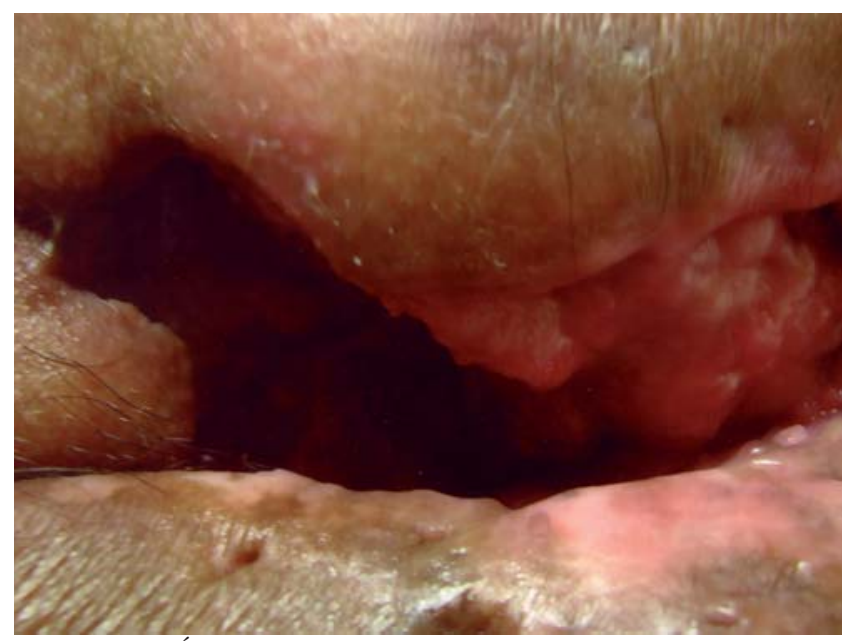

FiguRA 2: Úlcera sacral sem secreção, após a terceira infusão.

para tratamento da doença de Crohn e Artrite Reumatóide. $^{9,10}$ No entanto, não há na literatura ensaios clínicos controlados para quantificar e comprovar eficácia desta medicação. Considerando que sucessos terapêuticos têm um apelo maior para publicação do que as falhas, é possível que a eficácia do infliximabe na HS seja superestimada. O presente caso ilustra que o uso do infliximabe para o tratamento da HS não é uma garantia de sucesso. Indubitavelmente, o desenvolvimento de estudos controlados com maior número de pacientes contribuirá para a melhor seleção destes e para a escolha racional do infliximabe, nos casos em que este medicamento for a melhor opção terapêutica. 


\section{REFERÊNCIAS}

1. Kurzen H, Kurokawa I, Jemec GB, Emtestam L, Sellheyer K, Giamarellos-Bourboulis EJ, et al. What causes hidradenitis supurativa? Exp Dermatol. 2008; 17:455-472.

2. Naldi L. Epidemiology. In: Jemec G, Revuz J. Leyden J, eds. Hidradenitis suppurativa. vol 1. Germany: Springer 2006. p. 58-64.

3. Hay RJ, Adriaans BM. Bacterial infections. In: Rook's textbook of dermatology. Oxford: Blackwell Publishing; 2004. p.27.82-84.

4. Ackerman AB, Böer A, Bennin B, Gottlieb GJ. Histologic Diagnosis of Inflammatory Skin Diseases. An Algorithmic Method Based on Pattern Analysis. 3rd ed. New York: Ardor Scribendi; 2005.

5. Fardet L, Dupuy A, Kerob D, Levy A, Allez M, Begon E, et al. Infliximab for severe hidradenitis suppurativa:transient clinical efficacy in 7 consecutive patients. J Am Acad Dermatol. 2007;56:624-8.

6. Adams DR, Gordon KB, Devenyi AG, Ioffreda MD. Severe hidradenitis suppurativa treated with infliximab infusion. Arch Dermatol. 2003;139:1540-2.

7. Fernández-Vozmediano JM, Armario-Hita JC. Infliximab for the treatment of hidradenitis suppurativa. Dermatology. 2007; 215:41-4.
8. Thielen AM, Barde C, Saurat JH. Long-term infliximab for severe hidradenitis suppurativa. $\mathrm{Br} \mathrm{J}$ Dermatol. 2006;155:1105-6.

9. Sullivan TP, Welsh E, Kerdel FA, Burdick AE, Kirsner RS. Infliximab for hidradenitis suppurativa. Br J Dermatol. 2003;149:1046-9.

10. Lebwohl B, Sapadin AN. Infliximab for the treatment of hidradenitis suppurativa. J Am Acad Dermatol. 2003;49(5 Suppl):S275-6.

ENDEREÇO PARA CORRESPONDÊNCIA / MAILING ADDRESS: Daniel Lago Obadia

Rua Nossa Senbora de Lourdes, 83-102. Grajaú 20540370 Rio de Janeiro, RJ

Tel.:/Fax: $2125778753 ; 25876622$

e-mail: danielobadia@botmail.com

Como citar este artigo/How to cite this article: Obadia DL, Daxbacher ELR, Jeunon T, Gripp AC. Hidradenite supurativa tratada com infliximabe. An Bras Dermatol. 2009;84(6):695-7. 